\title{
Synthesis of Large-Scale Transition Metal Dichalcogenides for Their Commercialization
}

\author{
Received October 5, 2020; revised October 26, 2020; accepted October 29, 2020
}

\author{
Seoung-Woong Park ${ }^{\mathrm{a}, \mathrm{b}}$, Yong Jun Jo ${ }^{\mathrm{a}}$, Sukang Bae ${ }^{\mathrm{a}}$, Byung Hee Hong ${ }^{\mathrm{b}}$, and Seoung-Ki Lee ${ }^{\mathrm{a}, *}$ \\ ${ }^{a}$ Functional Composite Materials Research Center, Institute of Advanced Composite Materials, Korea Institute of Science and Technology \\ (KIST), Jeonbuk 55324, Republic of Korea \\ bepartment of Chemistry, Seoul National University, Seoul 08826, Republic of Korea
}

*Corresponding author E-mail: sklee@kist.re.kr

\begin{abstract}
Transition metal dichalcogenides (TMDC) have been identified as excellent platforms for developing the next-generation commercial flexible logic devices and sensors, owing to their outstanding mechanical, optical, and electrical properties. The TMDCs can be used to produce novel form-factors for wearable electronic devices. Typically, synthesis of large-scale TMDC thin film have been achieved by complexity vacuum-based approach. Therefore, it is essential to develop a simple and effective method to boost-up mass production of TMDC thin films on a large scale upon arbitrary substrates. In this regard, the solution-based TMDC synthesis method is advantageous because it proposes a simplification of the fabrication processes and an easy scaling-up of the material with a non-vacuum system. In this review, we summarize the evolution of the solution-based thin-film preparation and synthesis of the TMDCs; subsequently, we discuss the merits and drawbacks of the recently developed methods to form TMDC thin films directly from the deposited precursor. Finally, we discuss the practical applications of the TMDC thin films, which demonstrate the feasibility of their commercialized applications in electronic devices and sensors.
\end{abstract}

Keywords: Transition metal dichalcogenide, Large-scale synthesis, Solution-based process, Transistor, Sensor, Hydrogen evolution reaction

\section{Introduction}

Two-dimensional (2D) materials provide a versatile platform for investigating various electronic and optoelectronic phenomena. Since the exfoliated graphene was demonstrated in 2004, 2D materials have been one of the central research topics in the last two decades in the field of material science [1], physics [2], and electronics, [3,4] providing. Various merits and applications of 2D materials have been verified through numerous analytical methods. In the next step, the synthesis of large-area 2D materials for their commercialization has become the focus of subsequent investigations. Bae et al. [5] developed the method of scaling-up of graphene, grown up to 30 inches by the chemical vapor deposition (CVD) method. Since then, various progressive strategies have been introduced for the production of highquality graphene, even by companies, such as Sony [6] and Samsung [7]. The successful scalability of graphene boosted the mass production of other 2D materials, which belong to the family of transition metal dichalcogenide (TMDC) [8]. The TMDCs, which have semiconducting characteristics, are preferred as the target materials for developing the next-generation electronic devices because of their unique properties, such as direct or indirect band gap modulation [9], quantum-confinement [10], transparency [11], and flexibility [12]. Therefore, the uniform synthesis of TMDCs on a large-scale is important to accelerate their mass production [13,14]. Large-area TMDC thin films can be successfully fabricated via CVD, which can be used to grow vertically or horizontally stacked heterostructures [15-17]. However, the CVD- based synthesis is limited by several factors, such as the requirement of high temperatures $\left(\approx 1000{ }^{\circ} \mathrm{C}\right)$, difficulties in modulating the deposited film thickness to a desired value, and long processing time, which cause delay in the material preparation [18]. Recently, solutionphase deposition methods have been reported, which have several technical advantages, such as relatively low processing temperature [19], compatibility with various substrates, including polymer film (e.g. polyimide (PI)) [20], easily controlled layer thickness [20], rapid synthesis, and scalability with the help of existing coating techniques [21]. Recently, the lithography-free approach has been developed to form patterns directly on a TMDC film [22-24]. In this paper, we review an industrially applicable solution-based TMDC synthesis method, involving trial and error of the solution-phase deposition and its underlying mechanisms. Further, we discuss the corresponding applications, such as in transistors, sensors, and diodes, in detail. The achievements of the advanced synthesis method include large-scale fabrication of novel TMDC thin films for industrial applications.

\section{Synthesis of TMDC thin films by thermolysis}

Solution-phase synthesis of TMDC thin film is generally performed in several steps: the preparation of a precursor solution, deposition of the precursor, and conversion of the precursor's chemical structure. The thickness or uniformity of the synthesized TMDC film can be adjusted by controlling the precursor concentration, solution composition, and coating environment. In this section, we 
review the development of various deposition and synthesis methods for fabricating TMDC thin films.

\subsection{Two-step thermolysis of the TMDC film}

\section{Principles of thermolysis}

The solution-deposited TMDC compounds are usually synthesized by thermolysis of a precursor $[\mathrm{A}]_{n b}[\mathrm{MX}]_{a+n}$, where $\mathrm{A}$ is a cation that facilitates dissolution in the solvent, $\mathrm{M}$ is a transition metal, and $\mathrm{X}$ is a chalcogen that produces charge balance between $\mathrm{A}$ and $\mathrm{M}$ to support the precursor structure. MX is the anion in the precursor structure. This MX anion has a high bonding strength, which maintains its structure via the chalcogen bonding.

For example [Fig. 1(a)], synthesis of $\mathrm{MoS}_{2}$ requires an ammonium thiomolybdate $\left(\left[\mathrm{NH}_{4}\right]_{2}\left[\mathrm{Mo}_{3} \mathrm{~S}_{13} \cdot 2 \mathrm{H}_{2} \mathrm{O}\right]\right)$ precursor and a two-step thermolysis [25]. The precursor dissolves in a solvent as an anion $\left[\mathrm{Mo}_{3} \mathrm{~S}_{13}\right]^{2-}$ and a cation $\left[\mathrm{NH}_{4}\right]^{2+}$. In the first step, at temperatures $120 \leq T \leq 360{ }^{\circ} \mathrm{C}$ (where $T$ represents temperature), the $\left[\mathrm{Mo}_{3} \mathrm{~S}_{13}\right]^{2-}$ clusters cleave along an intermolecular bonding weakness to produce sulfur as $\mathrm{H}_{2} \mathrm{~S}$. Additionally, as the bond strength of the $\mathrm{Mo}-\mathrm{Mo}$ bond in $\mathrm{Mo}_{3} \mathrm{~S}_{13}$ obtained by a thermal reaction gradually weakens, it decomposes to amorphous $\mathrm{MoS}_{4}$. Subsequently, for $T \geq 440{ }^{\circ} \mathrm{C}$, the remaining Mo-S bond breaks to yield a poorly crystallized $\mathrm{MoS}_{2}$. The second thermolysis reaction produces sulfur as well as emits $\mathrm{H}_{2} \mathrm{~S}$ gas that escapes from the precursor, thereby producing a sulfur vacancy; therefore, to ensure a stable reaction, $\mathrm{H}_{2}$ or $\mathrm{H}_{2} \mathrm{~S}$ gas is injected constantly into the reaction chamber. On completion of the reaction, $\mathrm{MoS}_{2}$ is synthesized as a bulk structure (rod, wire, and dot) instead of being deposited on a specific substrate [Fig. 1(a), right]. Generally, $\left[\mathrm{NH}_{4}\right]_{2}\left[\mathrm{Mo}_{3} \mathrm{~S}_{13}\right]$ has a high molecular weight; therefore, it is difficult to control the layer thickness, and this drawback impedes the formation of atomically thin TMDC films.

As an alternative precursor, ammonium tetrathiomolybdate (ATM, $\left[\mathrm{NH}_{4}\right]_{2} \mathrm{MoS}_{4}$ ) is used to facilitate thermal decomposition for the fabrication of the $\mathrm{MoS}_{2}$ film [18] [Fig. 1(b)]. In the ATM structure, $\left[\mathrm{NH}_{4}\right]_{2}$ is a cation; Mo maintains the bonding as the center of the precursor, and $\mathrm{S}_{4}$ maintains the precursor structure. Prior to the two-step thermolysis, ATM is deposited on a specific substrate and all residual solvents are removed by heating at $100{ }^{\circ} \mathrm{C}$. Next, amorphous $\mathrm{MoS}_{3}$ is synthesized at $120 \leq T \leq 360{ }^{\circ} \mathrm{C}$ in the first thermolysis step. In the second thermolysis step, a thin film of $\mathrm{MoS}_{2}$ is synthesized under an atmosphere of a mixture of $\mathrm{Ar}$ and $\mathrm{S}$ (i.e., $\mathrm{Ar}+\mathrm{S}$ ), with $\mathrm{Ar}$ injected into the chamber at $T \geq 440{ }^{\circ} \mathrm{C}$. The crystallinity of thermally decomposed $\mathrm{MoS}_{2}$ can be improved by increasing $T$ to $820{ }^{\circ} \mathrm{C}$ during the second thermolysis step [26].

\section{Characteristics}

The Raman spectral characteristics are generally used to analyze the intrinsic property of the TMDCs $\left(\mathrm{MoS}_{2}, \mathrm{WS}_{2}, \mathrm{MoSe}_{2}, \mathrm{WSe}_{2}\right.$, and etc). Liu et al. [12,27] comparatively analyzed the Raman spectrum of the thermally decomposed $\mathrm{MoS}_{2}$ films on sapphire substrate, under $\mathrm{Ar}$ and $\mathrm{Ar}+\mathrm{S}$ atmosphere. Figure 1(c) shows two representative Raman absorption peaks, which are ascribed to the $E_{2 g}^{1}$ and $A_{1 g}$ modes of the $\mathrm{MoS}_{2}$ vibration. The $\mathrm{E}_{2 \mathrm{~g}}^{1}$ mode reflects the in-plane vibration and $\mathrm{A}_{1 \mathrm{~g}}$ mode reflects the out-of-plane vibration of the $\mathrm{MoS}_{2}$ as the difference in the energy level of electron from Raman absorption. A higher intensity of the Raman peak implies a better quality of the $\mathrm{MoS}_{2}$ film. Therefore, the sulfur gas aids in the filling of the sulfur vacancy, thereby enhancing the quality of the $\mathrm{MoS}_{2}$ film during thermolysis. In
Fig. 1(d), the frequency difference between the $A_{1 g}$ and $E_{2 g}^{1}$ modes $\left(\triangle \omega=\omega_{\mathrm{A}_{\mathrm{gg}}}-\omega_{\mathrm{E}_{2 \mathrm{~g}}}\right)$ can be used to identify the number of layers of the synthesized $\mathrm{MoS}_{2}$ [Fig. 1(d), bottom]. The Raman mode spacing is considerably narrow $\left(\Delta \omega \approx 25 \mathrm{~cm}^{-1}\right.$ ), which indicates that the $\mathrm{MoS}_{2}$ film is composed of five layers; a mono layer has $\Delta \omega \approx 16.5 \mathrm{~cm}^{-1}$ $[28,29]$. As the number of layers of the synthesized $\mathrm{MoS}_{2}$ approaches one, this synthesized monolayer develops a direct band gap and has optical properties; it absorbs light of a specific wavelength $(672 \mathrm{~nm})$. Figure 1(e) shows the photoluminescence (PL) of a tri-layer $\mathrm{MoS}_{2}$ film, thermally decomposed on a sapphire substrate. The PL peaks also exhibit a stronger intensity when $\mathrm{Ar}+\mathrm{S}$ gas mixture is injected; the result indicates that a $\mathrm{MoS}_{2}$ film of better quality is formed. Next, $\mathrm{X}$-ray photoelectron spectroscopy (XPS) analysis was conducted to identify the chemical composition of the thermally decomposed $\mathrm{MoS}_{2}$ film [Fig. 1(f)]. The Mo 3d shows two peaks at 229.3 and $232.5 \mathrm{eV}$, which are attributed to Mo $3 \mathrm{~d}_{5 / 2}$ and $\mathrm{S} 2 \mathrm{~s}$ peaks, indicating that the chemical composition of the $\mathrm{MoS}_{2}$ film exists during the $2 \mathrm{H}$ phase formation. The $S 2 p$ peaks, shown in the inset, indicate the intramolecular bonding of divalent sulfide ions $\left(\mathrm{S}^{2-}\right)$. Accordingly, the two distinguished peaks are observed approximately at 163.3 and $162 \mathrm{eV}$, corresponding to the $S 2 p_{1 / 2}$ and $S 2 p_{3 / 2}$ orbital splits. As a result, it is possible to verify the intrinsic chemical composition of $\mathrm{MoS}_{2}$ through the thermolysis of $\left[\mathrm{NH}_{4}\right]_{2} \mathrm{MoS}_{4}$. Additionally, the thickness modulation of a synthesized $\mathrm{MoS}_{2}$ film can be demonstrated by adjusting the concentration of the ATM precursor [20]. Figure 1(f) shows the atomic force microscopy (AFM) image of a $\mathrm{MoS}_{2}$ thin film, synthesized through a two-step thermolysis reaction with different concentrations of ATM precursor. Thus, a $\mathrm{MoS}_{2}$ thin film, with one $(0.65 \mathrm{~nm})$ to a few layers $(3.2 \mathrm{~nm})$, can be synthesized by a two-step thermolysis method.

\subsection{Synthesis of TMDC films on a large scale}

To synthesize a TMDC film from a solution on an arbitrary substrate (e.g., $\mathrm{SiO}_{2} / \mathrm{Si}$ and sapphire), it is important to monitor the precursor deposition since it determines the scale, thickness, and patterning of the TMDC films. Here, we first describe the dip coating deposition method, which is proposed by Liu et al. [27]. In this method, $\left(\mathrm{NH}_{4}\right)_{2} \mathrm{MoS}_{4}$ is dissolved in dimethylformamide (DMF) to form a precursor solution. $\mathrm{A} \mathrm{SiO}_{2}$ substrate that is prepared via the oxygen treatment is immersed into the $\left(\mathrm{NH}_{4}\right)_{2} \mathrm{MoS}_{4}$ solution. Next, the substrate is pulled out slowly $\left(0.5 \mathrm{~mm} \mathrm{~s}^{-1}\right)$ from the solution. The deposition yield of $\left(\mathrm{NH}_{4}\right)_{2} \mathrm{MoS}_{4}$ film is determined by the precursorsubstrate wettability and separation speed. The process is very simple; however, controlling the thickness of the precursor layer is difficult; thus, this method is not suitable for the mass production of TMDC films.

Figure 2(a) illustrates the spin-coating strategy to obtain waferscale $\mathrm{MoS}_{2}$ thin films through the dissolution of $\left(\mathrm{NH}_{4}\right)_{2} \mathrm{MoS}_{4}$ in nmethylpyrolidone (NMP) [30]. Spin coating is widely used to deposit photoresists during the semiconductor manufacturing; the coating thickness can be controlled easily by varying the rotation speed. Therefore, using the spin coating method, the precursor film thickness can be controlled by varying the concentration of the solution and rotating speed, thereby yielding precisely tuned mono-/bi-/tri-layers of the thermally decomposed $\mathrm{MoS}_{2}$ film. Spin coating is advantageous for thickness control; however, only one solvent is used; therefore, the wetting of a substrate is low. As a result, the viscosity or surface tension 
(a)

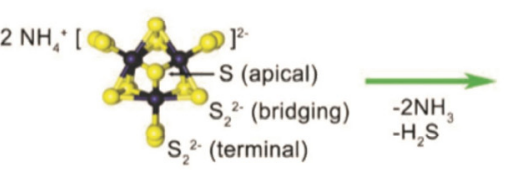

$\left(\mathrm{NH}_{4}\right)_{2}\left[\mathrm{Mo}_{3} \mathrm{~S}_{13}\right]$

(b)

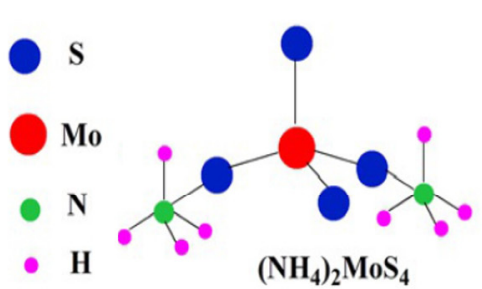

(c)

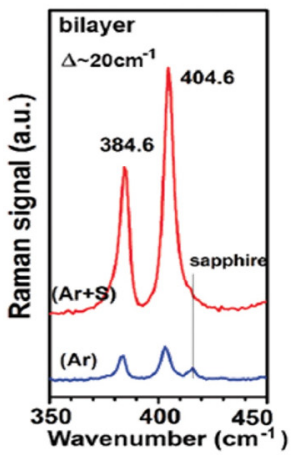

(d)

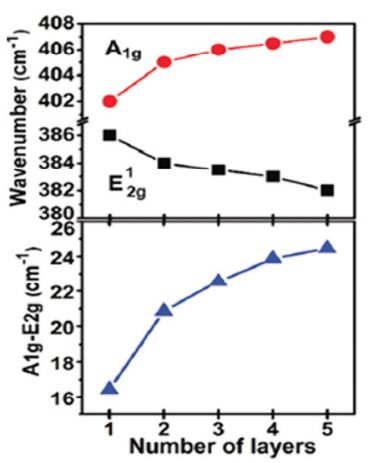

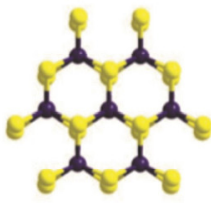

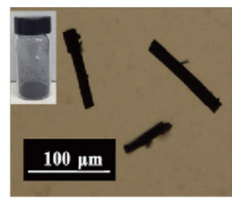

$\mathrm{MoS}_{2}$

Poorly crystalline at $440{ }^{\circ} \mathrm{C}$

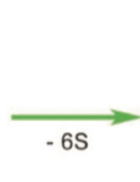

and

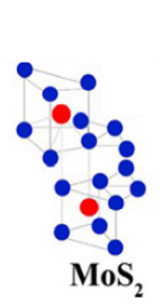

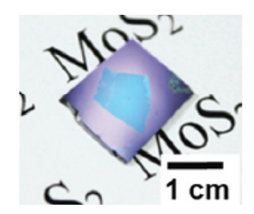

$\mathrm{MoS}_{3}$

(e)

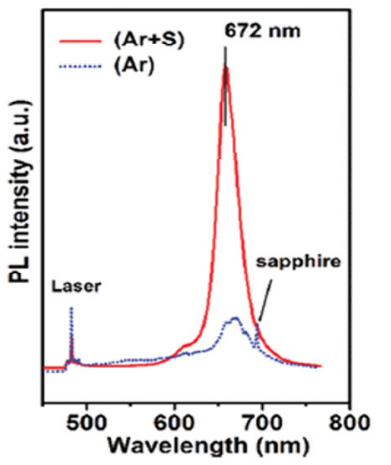

(f)

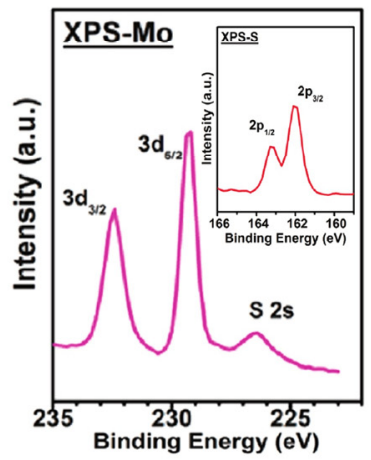

(g)

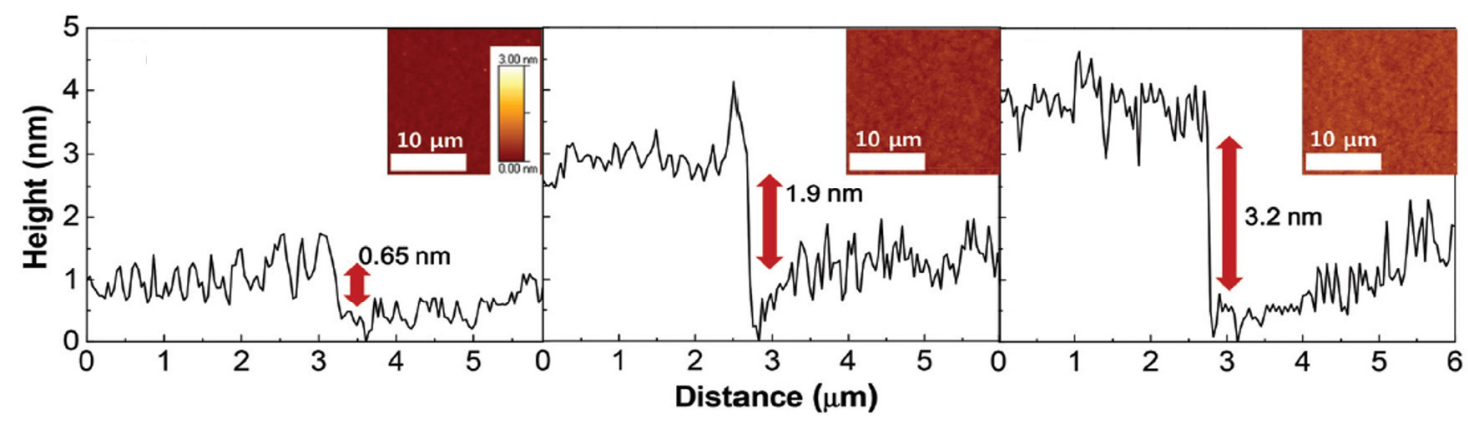

Figure 1. (a) Schematic of the chemical composition of bulk-type $\mathrm{MoS}_{2}$ formation from $\left(\mathrm{NH}_{4}\right)_{2}\left[\mathrm{Mo}_{3} \mathrm{~S}_{13}\right.$ ]. (Reprinted with permission from [18] (A. Giri et al., Adv. Mater. 30, 1707577 (2018)), @ 2020, John Wiley and Sons). Optical microscope image of rod-type MoS $_{2}$ (right). (Reprinted with permission from [43] (Z. Huang et al., Angew. Chem. Int. Ed. Engl. 54, 15181 (2015)), ( ) 2020, Elsevier). (b) Schematic representation of the synthesis of thin-film MoS 2 via two-step thermolysis from $\left(\mathrm{NH}_{4}\right)_{2}\left[\mathrm{MoS}_{4}\right]$. $(\mathrm{Reprinted}$ with permission from [44] (T. Zhang et al., Chem. Asian J. 11, 1392-2398 (2016)), @ 2020, John Wiley and Sons). Optical microscopic image of synthesized $\mathrm{MoS}_{2}$ thin film on $\mathrm{SiO}_{2} / \mathrm{Si}$ substrate (right). (c) Raman spectra of two-step thermally decomposed $\mathrm{MoS}_{2}$ under $\mathrm{Ar}$ or $\mathrm{Ar}+\mathrm{S}$ atmosphere. (d) Energies of the two characteristic peaks: Variation of the spacing between $E_{2 g}$ and $A_{1 g}$ with number of $M_{0} S_{2}$ layers. (e) PL intensity of the thermally decomposed triple layered $M_{0} S_{2}$ film. (f) XPS spectra of the thermally decomposed MoS film: Mo 3d and S 2s peaks. (Reprinted with permission from [27] (Liu et al., Nano Letters 12, 1538-1544 (2012)), @ 2020, American Chemical Society). (g) Surface topographic images (insets) and cross-sectional height profile of the thermally decomposed $\mathrm{MoS}_{2}$ with thickness modulation by adjusting $\left(\mathrm{NH}_{4}\right)_{2}\left[\mathrm{MoS}_{4}\right]$ concentration. $(\mathrm{Reprinted}$ with permission from [20] (H. Yang et al., Nanoscale 7, $9311-9319$ (2015)), @ 2020, Royal Society of Chemistry).

of a precursor cannot be controlled easily. Therefore, this method is useful only to synthesize TMDC films on a relatively small scale.

Yang et al. [20] proposed a solution engineering that can easily control the wetting of precursors in the solution with the substrate.
The DMF-based $\left(\mathrm{NH}_{4}\right)_{2} \mathrm{MoS}_{4}$ solution is reformulated additionally with two types of amino alcohol-based solvents. Before the spin coating, an oxygen plasma surface treatment is applied to increase the wettability of the precursor solution with the substrate. The quality of 
(a)

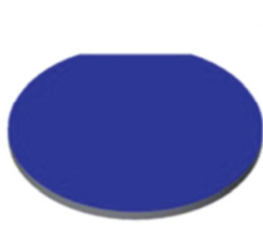

$\mathrm{Si} / \mathrm{SiO}_{2}$ Wafer

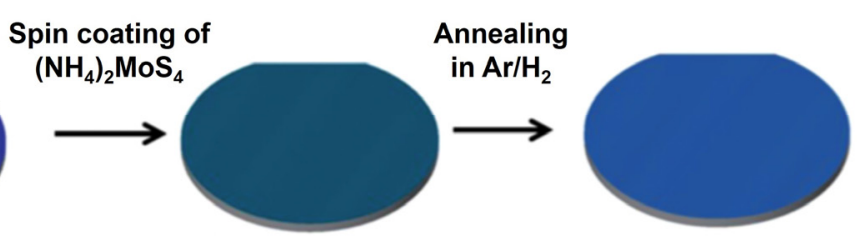

$\left(\mathrm{NH}_{4}\right)_{2} \mathrm{MoS}_{4}$ Thin film
Atomically thin $\mathrm{MoS}_{2}$ film

(b)

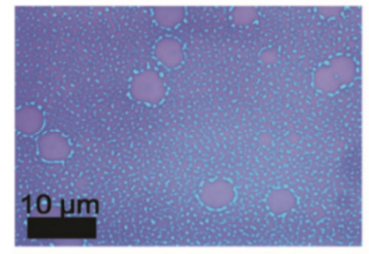

(c)
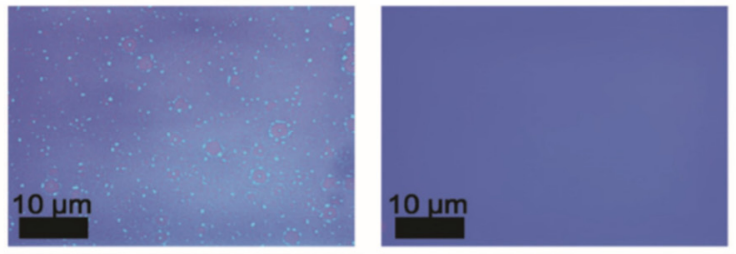

(d)

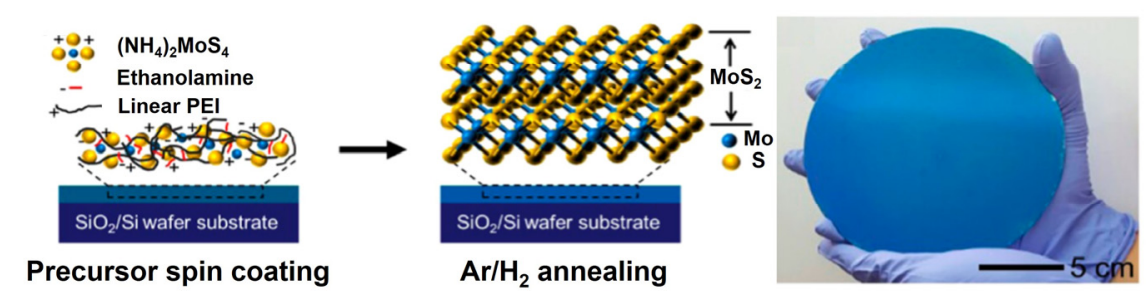

(e)
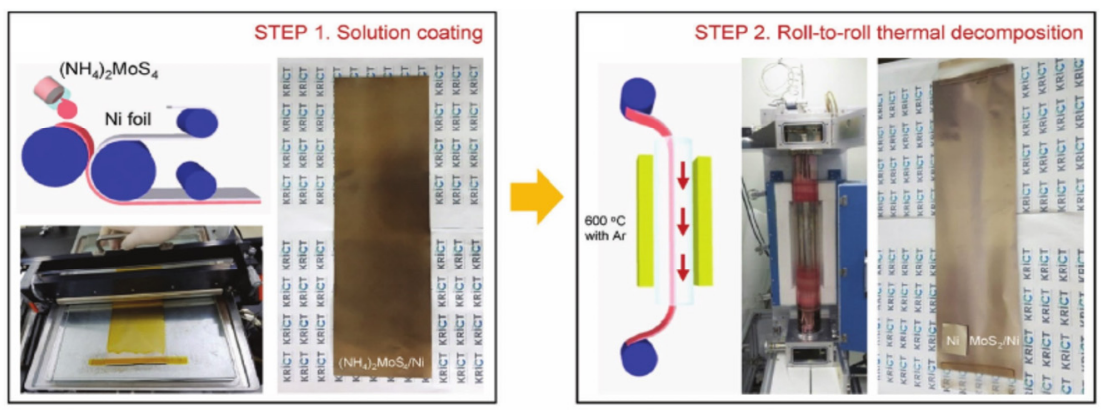

Figure 2. (a) Schematic representation of spin coating based 4 inch scaled $\mathrm{MoS}_{2}$ thin-film synthesis. (Reprinted with permission from [30] (A.S. Gergo et al., Adv. Funct. Mater. 24, 7461-7466 (2014)), @ 2020, John Wiley and Sons). (b) Optical microscope images of the spin coated $\left(\mathrm{NH}_{4}\right)_{2}\left[\mathrm{MoS} \mathrm{S}_{4}\right]$ films using different compositions of the solvent. (Reprinted with permission from [20] (Yang et al., Nanoscale 7, 9311-9319 (2015)), ( 2020 , Royal Society of Chemistry). (c), (d) Schematic diagram of the polymer-assisted spin coated $\left(\mathrm{NH}_{4}\right)_{2}\left[\mathrm{MoS}_{4}\right]$ film and its thermal decomposition on a 6-inch scaled $\mathrm{SiO}_{2} / \mathrm{Si}$ wafer. (Reprinted with permission from [21] (Yang et al., Chem. Mater. 29, $5772-5776$ (2017)), (c) 2020, American Chemical Society). (e) Schematic illustration and photographs of the roll-to-roll based 20-inch scaled MoS ${ }_{2}$ thin-film synthesis: solution coating and thermal decomposition. (Reprinted with permission from [32] (Y. Lim et al., Adv. Mater. 30, 1705270 (2018)), ๑ 2020, John Wiley and Sons).

the spin-coated precursor film is gradually improved owing to the additive solvent [Fig. 2(b), left to right]. During the spin coating of the precursor, the additive solvent promotes the solvation of $\left(\mathrm{NH}_{4}\right)_{2} \mathrm{MoS}_{4}$ with balanced viscosity and surface tension. An optimized solvent mixture of DMF:n-butylamine:2-aminoethanol = 4.5:4.5:1 (v/v/v, where $\mathrm{v}$ represents volume) generates a uniform spin-coating of the precursor, without pinholes or dewetted regions. Ionescu et al. [31] reported a spin coating technique, wherein the $\left(\mathrm{NH}_{4}\right)_{2} \mathrm{MoS}_{4}$ precursor is dissolved into a dimethyl sulfoxide (DMSO):ethylenediaminetetraacetic acid (EDTA) co-solvent. During the spin coating, the DMSO increases the wettability between the $\left(\mathrm{NH}_{4}\right)_{2} \mathrm{MoS}_{4}$ precursor and $\mathrm{SiO}_{2}$ substrate, and
EDTA stabilizes the precursor by chelation. Another method of improving the synthetic area of the $\mathrm{MoS}_{2}$ thin film is the polymerassisted precursor deposition technique, which was engineered by Yang et al. [21]. A linear polymer matrix (poly ethyleneimine, PEI) [Fig. 2(c)] allows the viscosity modulation of $\left(\mathrm{NH}_{4}\right)_{2} \mathrm{MoS}_{4}$ precursor with full coverage of the spin-coated $\mathrm{MoS}_{2}$ on a 6-inch $\mathrm{SiO}_{2} / \mathrm{Si}$ wafer [Fig. 2(d)]. The film thickness can be tuned by adjusting the concentration of the $\left(\mathrm{NH}_{4}\right)_{2} \mathrm{MoS}_{4}$ precursor.

Although the solution-engineered precursor deposition method increases the film area, this method has several drawbacks, such as low production yield, differences in the crystal growth depending on the 
(a)

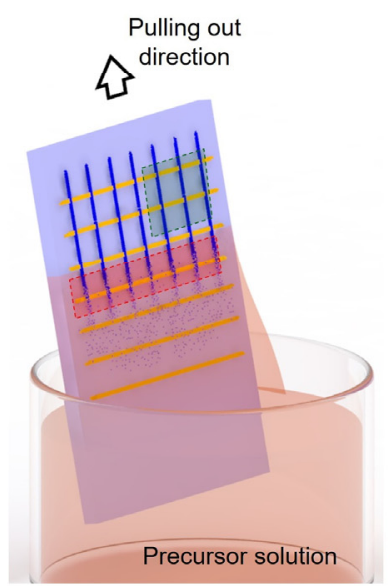

(f)

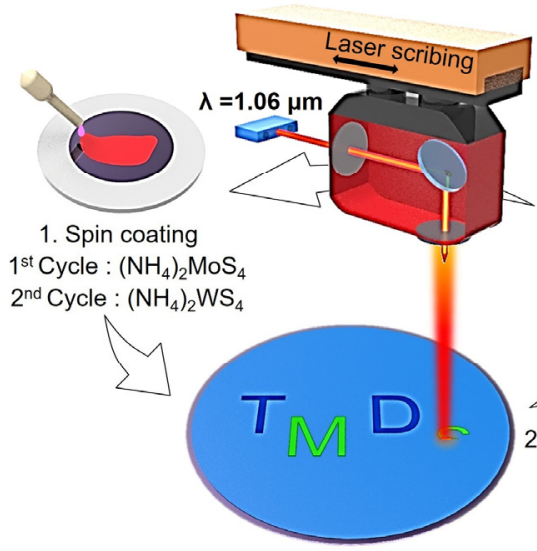

(b)

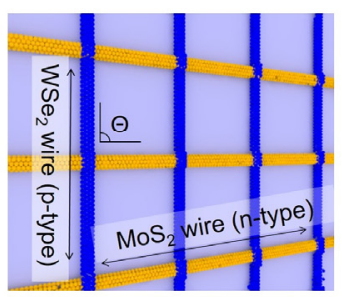

(d)

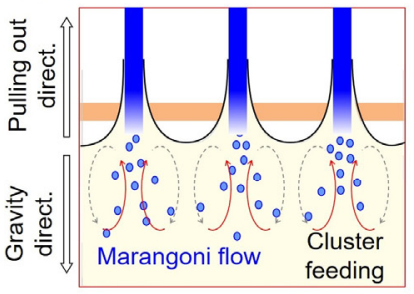

(c)

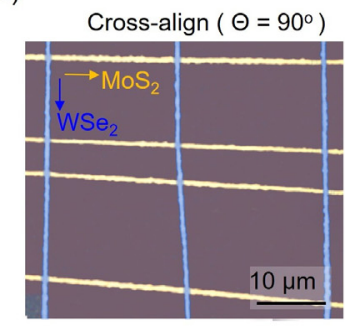

(e)

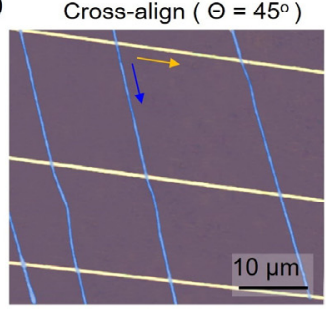

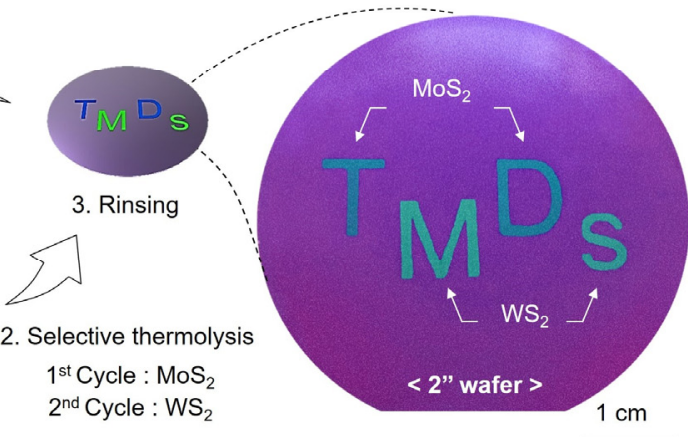

Figure 3. (a) Schematic diagram representing the synthesis of self-assembled $W_{2} e_{2} / \mathrm{MoS}_{2}$ wires. (b), (c) Images of cross-aligned WSe $/ \mathrm{MoS}_{2}$ wires showing their growth directions. (d), (e) Optical microscopy images of different angles of $\mathrm{WSe}_{2} / \mathrm{MoS}_{2}$ wires: $90^{\circ}$ and $45^{\circ}$. (Reprinted with permission from [22] (Lee et al., Adv. Mater. 31, 1904194 (2019)), ( ) 2020, John Wiley and Sons). (f) Illustration of $\mathrm{MoS}_{2}$ and $\mathrm{WS}_{2}$ pattern formation, including spin coating, photothermal decomposition, and rinsing. (g) Photograph of the patterned $\mathrm{MoS}_{2}$ and $\mathrm{WS}_{2}$ supported on a 2-inch $\mathrm{SiO}_{2} /$ Si wafer. (Reprinted with permission from [23] (Park et al., ACS Nano 14, 8485-8494 (2020)), ( 2020, American Chemical Society).

substrate, and high production cost. Owing to these limitations, Lim et al. [32] developed a synthetic method of producing 20-inch-scale $\mathrm{MoS}_{2}$ thin films using a roll-to-roll process [Fig 2(e)]. They suggested that spray coating of the $\left(\mathrm{NH}_{4}\right)_{2} \mathrm{MoS}_{4}$ precursor on a $\mathrm{Ni}$ foil can improve the production yield and crystallinity [33]. The precursor deposited film is heated in a furnace at $800{ }^{\circ} \mathrm{C}$ under Ar or $\mathrm{H}_{2}$ atmosphere to thermally decompose the $\left(\mathrm{NH}_{4}\right)_{2} \mathrm{MoS}_{4}$ precursor. This method significantly increases the production of the $\mathrm{MoS}_{2}$ thin films on a large scale. A high yield can be achieved by controlling the various process parameters.

\section{Synthesis of direct-patterned TMDC films}

To use a TMDC thin film in a practical electronic device, the fabricated film should be isolated to form a source-drain array. Therefore, a TMDC pattern is typically fabricated via the additional photolithography or oxygen plasma treatment-based mask process. To simplify this process, the precursor deposition and synthesis methods have been developed to form TMDC patterns directly, without the additional patterning step. Lee et al. [34] demonstrated the direct pattern formation in the TMDC precursor film through a dip coating method for the synthesis of $\mathrm{WS}_{2}$ or $\mathrm{MoS}_{2}$ wires. In this process, a piece of $\mathrm{SiO}_{2}, \mathrm{Si}$, or quartz wafer is soaked in $\left(\mathrm{NH}_{4}\right)_{2} \mathrm{MoS}_{4}$ (or ammonium tetrathiotungstate, $\left.\left(\mathrm{NH}_{4}\right)_{2} \mathrm{WS}_{4}\right)$ solution in de-ionized water. Next, the $\mathrm{SiO}_{2}, \mathrm{Si}$, or quartz wafer is lifted in the upward direction, and the precursor is precipitated simultaneously in the form of a periodic wire. This method can yield both homostructured $\mathrm{WS}_{2}-\mathrm{MoS}_{2}$ wires and $\mathrm{WS}_{2} / \mathrm{MoS}_{2}$ heterostructured wires, under optimized parameters, such as proper $\mathrm{pH}$ and concentration of the aqueous precursor, required humidity and evaporation speed in the environment. The addition of isopropyl alcohol can tune the solvent's evaporation speed, thereby modulating the thickness of the precipitated precursor layer.

Later, Lee et al. [22] developed cross-aligned $\mathrm{WSe}_{2} / \mathrm{MoS}_{2}$ heterostructures through partial pinning of the solution to the substrate, which generates a regular and repetitive circular convection flow, i.e., Marangoni flow, during the precursor feeding [Fig. 3(a)]. The precursor nuclei in the solution continuously adhere to the $\mathrm{SiO}_{2} / \mathrm{Si}$ substrate; 
Table I. Comparison between the different methods of solution-processed TMDC thin film synthesis.

\begin{tabular}{|c|c|c|c|c|c|}
\hline $\begin{array}{l}\text { Precursor } \\
\text { Deposition }\end{array}$ & $\begin{array}{l}\text { Precursor } \\
\text { Solution }\end{array}$ & $\begin{array}{l}\text { Annealing } \\
\text { Method }\end{array}$ & $\begin{array}{l}\text { Synthetic } \\
\text { Area }\end{array}$ & Heterostructure & Reference \\
\hline $\begin{array}{l}\text { Dip coating } \\
\text { (full cover) }\end{array}$ & DMF & $\begin{array}{l}\text { Thermolysis } \\
\text { (furnace) }\end{array}$ & $1 \times 1 \mathrm{~cm}^{2}$ & $\mathrm{X}$ & {$[27]$} \\
\hline $\begin{array}{l}\text { Spin coating } \\
\text { (full cover) }\end{array}$ & NMP & $\begin{array}{l}\text { Thermolysis } \\
\text { (furnace) }\end{array}$ & 2 inch & $\mathrm{X}$ & {$[30]$} \\
\hline $\begin{array}{l}\text { Spin coating } \\
\text { (full cover) }\end{array}$ & DMF+Additive & $\begin{array}{l}\text { Thermolysis } \\
\text { (furnace) }\end{array}$ & 2 inch & $\mathrm{X}$ & {$[20]$} \\
\hline $\begin{array}{l}\text { Spin coating } \\
\text { (full cover) }\end{array}$ & DMF+DMSO & $\begin{array}{l}\text { Thermolysis } \\
\text { (furnace) }\end{array}$ & 4 inch & $\mathrm{X}$ & {$[31]$} \\
\hline $\begin{array}{l}\text { Spin coating } \\
\text { (full cover) }\end{array}$ & $\mathrm{DMF}+\mathrm{PEI}$ & $\begin{array}{l}\text { Thermolysis } \\
\text { (furnace) }\end{array}$ & 6 inch & $\mathrm{X}$ & {$[21]$} \\
\hline $\begin{array}{l}\text { Roll-to-Roll } \\
\text { (full cover) }\end{array}$ & ethylene glycol & $\begin{array}{l}\text { Thermolysis } \\
\text { (furnace) }\end{array}$ & 20 inch & $\mathrm{X}$ & {$[32]$} \\
\hline $\begin{array}{l}\text { Dip coating } \\
\text { (pattern) }\end{array}$ & DI water & $\begin{array}{l}\text { Thermolysis } \\
\text { (furnace) }\end{array}$ & $1 \times 1 \mathrm{~cm}^{2}$ & $\mathrm{O}$ & {$[34]$} \\
\hline $\begin{array}{l}\text { Dip coating } \\
\text { (pattern) }\end{array}$ & $\mathrm{DMF}$ & $\begin{array}{l}\text { Thermolysis } \\
\text { (furnace) }\end{array}$ & $1 \times 1 \mathrm{~cm}^{2}$ & $\mathrm{O}$ & {$[22]$} \\
\hline $\begin{array}{l}\text { Spin coating } \\
\text { (full cover) }\end{array}$ & DMF+Additive & $\begin{array}{l}\text { Locally Thermolysis } \\
\text { (pulsed laser) }\end{array}$ & 4 inch & $\mathrm{O}$ & {$[23]$} \\
\hline
\end{tabular}

therefore, vertically (directionally) heterostructured TMDC wires can be precipitated [Figs. 3(b) and 3(c)]. Such a direct method to form precursor patterns is useful to fabricate a specific heterojunction or to form patterns on a single material without using an additional patterning process. The fabricated cross-aligned wires show different cross-angles of $45^{\circ}$ and $90^{\circ}$; this arrangement is advantageous for producing stacked TMDCs to develop integrated electronic devices [Figs. 3(d) and 3(e)].

Park et al. [23] have recently developed a novel process that can freely form TMDC patterns through a pulsed laser annealing method. Using the precursor deposition method of Yang et al. [20], a precursor is initially deposited on a 4-inch TMDC thin film by spin coating. Next, a pulsed-laser source of wavelength $1.06 \mu \mathrm{m}$ is irradiated on the precursor to achieve photothermolysis [Figs. 3(f) and 3(g)]. As a result, a fine $\mathrm{WS}_{2}$ or $\mathrm{MoS}_{2}$ homostructure is formed with a $\mathrm{WS}_{2}$ or $\mathrm{MoS}_{2}$ vertical heterostructure pattern. This method allows the synthesis of a large-area patterned TMDC film only with a single-step heat treatment at room temperature and pressure in a shortened process time. Further, the fabrication is accomplished without the additional processes by easily blocking the external oxygen in a chalcogen gas (S, Se) rich atmosphere, wherein the gas is derived from the TMDC precursor. Details on the aforementioned synthesis methods are summarized in Table I.

\section{Applications of TMDCs}

TMDC thin films obtained from a solution (e.g., $\mathrm{MoS}_{2}, \mathrm{WS}_{2}$, $\mathrm{WSe}_{2}$ ) can be synthesized on a large scale using simple thermal decomposition processes and therefore have a variety of applications in electronic devices. In this section, we review the electronic devices and sensors that have been developed by using the solution-based synthesis methods.

\subsection{Field-effect transistors (FETs)}

One of the key characteristics of a TMDC thin film is its semiconducting property. A TMDC thin film has a tunable band gap depending on the number of its layers [35,36]. Liu et al. [27] first reported the fabrication of an FET from the solution-based thermally decomposed $\mathrm{MoS}_{2}$ thin films. The synthesized triple layered $\mathrm{MoS}_{2}$ film has the property of $n$-type behavior and shows good field-effect electron mobility $\left(4.7 \mathrm{~cm}^{2} \mathrm{~V}^{-1} \mathrm{~s}^{-1}\right)$. The variation of the electron mobility, depending on the number of layers of the solutionsynthesized $\mathrm{MoS}_{2}$ film, is systemically investigated by Lee and coworkers [34]. Figure 4(a) shows a comparison of the transfer curves $\left(\mathrm{I}_{D S} v s \mathrm{~V}_{G S}\right)$ associated with the thickness modulation of the ion-gel gated $\mathrm{MoS}_{2}$ wires. The transfer characteristics show that the current increases with increasing thickness of the wires ( 3 to $32 \mathrm{~nm}$ ). In the case of a thick $\mathrm{MoS}_{2}$ wire $(32 \mathrm{~nm})$ exhibits symmetric ambipolar behavior, indicating that enhanced electron and Hole mobility was observed. Figure 4(b) shows the variation of the mobility with the $\mathrm{MoS}_{2}$ film thickness. The statistically evaluated average effective mobility is approximately $100 \mathrm{~cm}^{2} \mathrm{~V}^{-1} \mathrm{~s}^{-1}$, as observed from Fig. 4(b). These results are due to the fact that, as the thickness of the $\mathrm{MoS}_{2}$ films increase, their vulnerability to carrier scattering decreases, which in turn increases their carrier mobility [37,38]. Several solution-synthesized $\mathrm{MoS}_{2}$ thin films have been applied to FETs. However, they have low average effective carrier mobility, $[20,31]$ and are therefore not suitable for commercialization. The performance of the solution-processed $\mathrm{MoS}_{2}$ FETs are summarized in Table II.

\subsection{Photodetectors}

Shifting the perspective to the optoelectronic properties of the solution-based $\mathrm{MoS}_{2}$ thin films, Lim et al. [33] developed a thermally decomposed $\mathrm{MoS}_{2}$-based visible light photodetector on a 4 -inch 
(a)

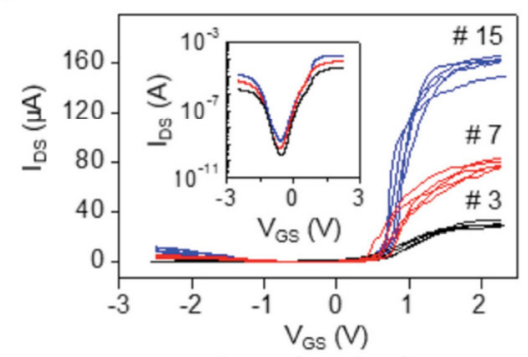

(c)

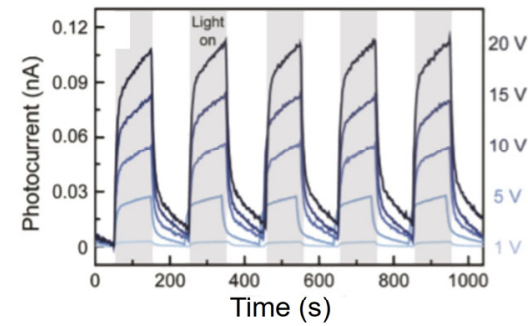

(e)

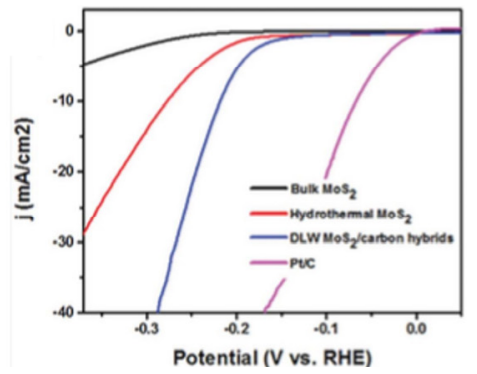

(b)

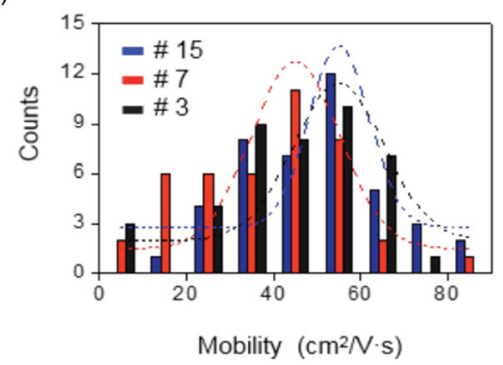

(d)

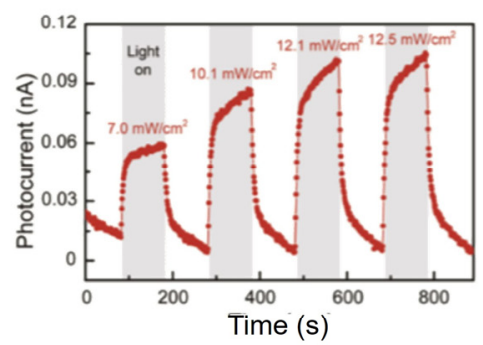

$(f)$

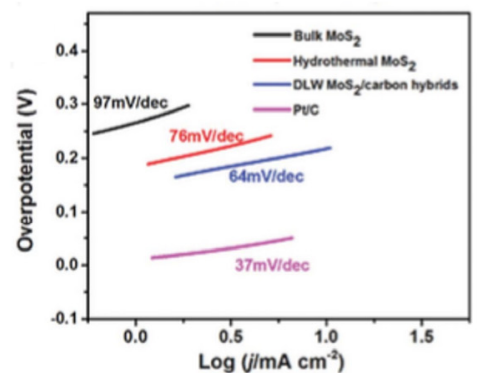

Figure 4. (a), (b) Transfer curves ( $\operatorname{lDS}_{S} v S V_{G S}$ ) of the ion-gel gated MoS 2 /graphene hybrid FETs, depending on the thickness of the wires in the channel and their effective charge mobility. (Reprinted with permission from [34] (Lee et al., Adv. Mater. 27, 4142-4149 (2015)), @ 2020, John Wiley and Sons). (c), (d) Time-resolved photocurrent response of the thermally decomposed MoS 2 on PI film (Reprinted with permission from [33] (Y. Lim et al., Adv. Mater. 28, 5025-5030 (2016)), @ 2020, John Wiley and Sons). (e), (f) Polarization curves of a series of samples: Pt/C, bulk MoS 2 , hydrothermal $\mathrm{MoS}_{2}$, and photothermally decomposed MoS 2 . (Reprinted with permission from [39] (Deng et al., J. Mater. Chem. A. 4, 6824-6830 (2016)), ( ) Royal Society of Chemistry).

Table II. Comparison of the performance of the FETs, produced by solution based-TMDC synthesis.

\begin{tabular}{|c|c|c|c|c|c|}
\hline Materials & Annealing Method & On/ Off Ratio & $\begin{array}{c}\text { Mobility } \\
\left(\mathrm{cm}^{2} \mathrm{~V}^{-1} \mathrm{~s}^{-1}\right)\end{array}$ & $\begin{array}{c}\text { Directly } \\
\text { Patterning }\end{array}$ & Reference \\
\hline $\mathrm{MoS}_{2}$ & $\begin{array}{l}\text { Thermolysis } \\
\text { (furnace) }\end{array}$ & $\sim 10^{5}$ & $\sim 4.7$ & $\mathrm{X}$ & [27] \\
\hline $\begin{array}{l}\mathrm{MoS}_{2} \\
\mathrm{WS}_{2}\end{array}$ & $\begin{array}{l}\text { Thermolysis } \\
\text { (furnace) }\end{array}$ & $\sim 10^{6}$ & $\sim 100$ & $\mathrm{O}$ & [34] \\
\hline $\mathrm{MoS}_{2}$ & $\begin{array}{l}\text { Thermolysis } \\
\text { (furnace) }\end{array}$ & $\sim 10^{4}$ & $\sim 0.24$ & $\mathrm{X}$ & [20] \\
\hline $\mathrm{MoS}_{2}$ & $\begin{array}{l}\text { Thermolysis } \\
\text { (furnace) }\end{array}$ & $\sim 10^{8}$ & $\sim 0.1$ & $\mathrm{X}$ & {$[31]$} \\
\hline $\begin{array}{l}\mathrm{MoS}_{2} \\
\mathrm{WS}_{2}\end{array}$ & $\begin{array}{l}\text { Locally Thermolysis } \\
\text { (pulsed laser) }\end{array}$ & $\sim 10^{3}$ & $\sim 6.4$ & $\mathrm{O}$ & [23] \\
\hline
\end{tabular}

$\mathrm{SiO}_{2} / \mathrm{Si}$ wafer. They focused on the spatial distribution of the large-scale $\mathrm{MoS}_{2}$ thin film with 100 devices (10 rows $\times 10$ columns). The result of the homogeneous photoresponse is displayed in Fig. $4(e)$, which indicates that the device yielded a periodically varying photocurrent under a halogen lamp irradiation with a tunable power, regardless of the bias voltages $(1,5,10,15$, and $20 \mathrm{~V})$. For a fixed photocurrent at a bias voltage of $20 \mathrm{~V}$, the illumination power increases from 7.0 to $12.5 \mathrm{~mW} \mathrm{~cm}^{-2}$; this observation implies that the photocurrent is proportional to the illumination power, owing to an increase in the carrier-generation rate. Thus, the photocurrent of a 
(a)

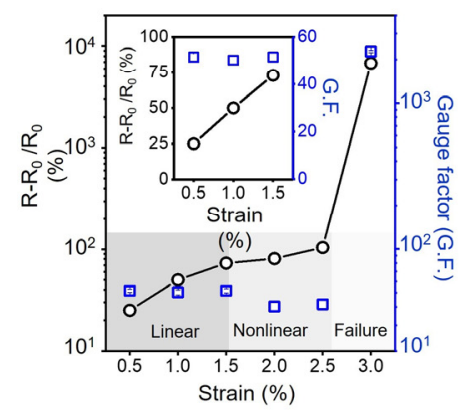

(b)

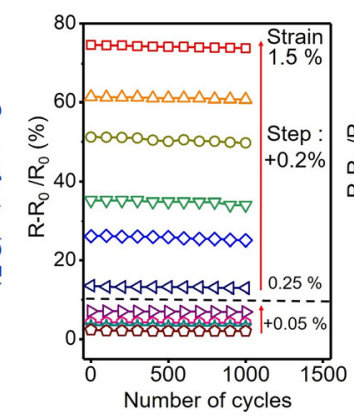

(c)

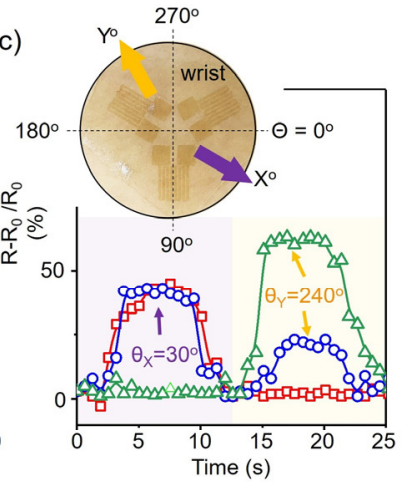

(d)

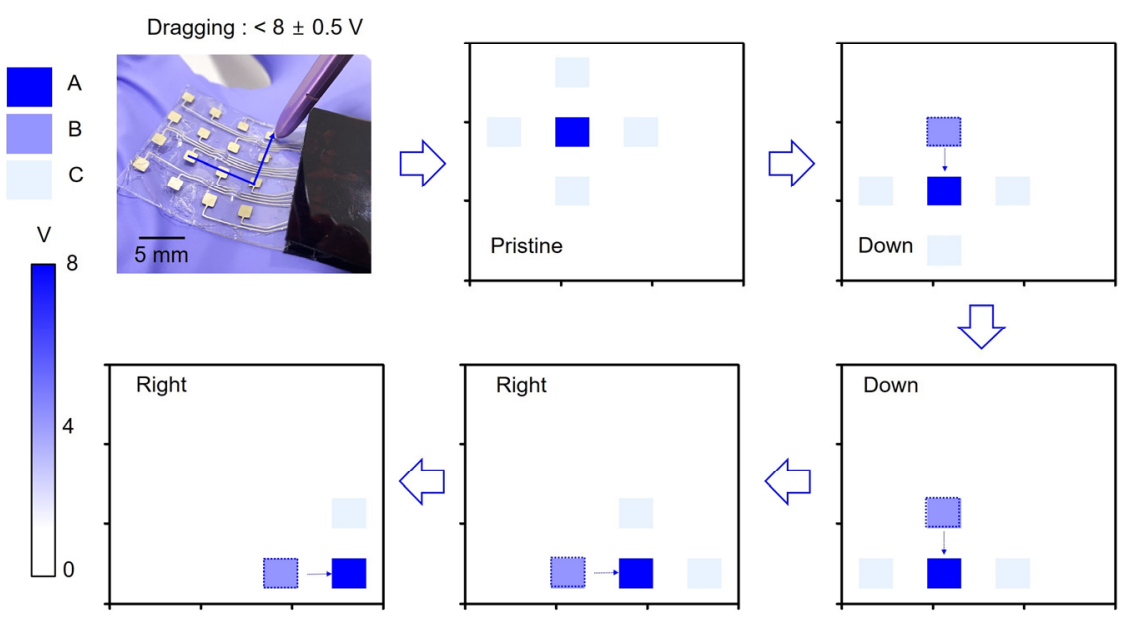

Figure 5. (a) Relative resistance variation and gauge factor of the $\mathrm{MoS}_{2}$-based strain gauge in the range of $0.5-3.0 \%$. (b) Mechanical stability of MoS 2 -based strain gauge up to 1000 cycles with different strain levels. (c) Operation of the $\mathrm{MoS}_{2}$-based 3-axis strain gauge rosette with sensing ability from unknown directions. (Reprinted with permission from [23] (Park et al., ACS Nano 14, 8485-8494 (2020)), @ 2020, American Chemical Society). (d) Time-resolved trajectory mapping of the MoS2-based haptic sensor using a stylus pen movement. (Reprinted with permission from [24] (Park et al., Nano Energy 78, 105266 (2020)), @ 2020, American Chemical Society).

photodetector is linearly dependent on the illumination power.

Furthermore, Lee et al. [22] recently demonstrated a solutionbased cross-aligned $\mathrm{WSe}_{2} / \mathrm{MoS}_{2} p$ - $n$ junction structured photodiode and detector. The analyzed photo responsivity of the fabricated device is $\sim 5.39 \mathrm{~A} \mathrm{~W}^{-1}$, which is higher than that of the previously reported TMDC-based optoelectronic devices that are made up of monolayer homo- and heterojunctions. Park et al. [23] demonstrated a $p$ - $n$ diode with vertically stacked solution-processed $\mathrm{WS}_{2} / \mathrm{MoS}_{2}$ thin films prepared by irradiating $\left(\mathrm{NH}_{4}\right)_{2} \mathrm{WS}_{4} / \mathrm{MoS}_{2}$ films with an ultra-short laser pulse $(\sim 100 \mathrm{ps})$ to cause selective thermolysis of $\left(\mathrm{NH}_{4}\right)_{2} \mathrm{WS}_{4}$, since it shows $\sim 60$ times higher absorbance than the $\mathrm{MoS}_{2}$ film during the laser annealing $(1.06 \mu \mathrm{m})$. The process converts $\left(\mathrm{NH}_{4}\right)_{2} \mathrm{WS}_{4}$ to a $\mathrm{WS}_{2}$ film with high crystallinity despite the instant formatting on the $\mathrm{MoS}_{2}$ lattice. This $p$ - $n$ diode that uses $\mathrm{WS}_{2} / \mathrm{MoS}_{2}$ produces good electrical rectification with a forward-to-reverse current ratio of $\sim 10^{3}$.

\subsection{Hydrogen evolution reactor (HER)}

Another solution-based TMDC application has attracted considerable attention in the field of catalysis. Deng et al. [39] developed hydrogen evolution reaction (HER) catalysts from the one-step photothermal decomposition of PI and $\mathrm{MoS}_{2}$ precursor by using a continuous-wave laser to ensure strong heating. The laser-irradiated sample must include a composite of laser-induced graphene and $\mathrm{MoS}_{2}$ nanoparticles; the composite significantly influences the HER activity by increasing the specific area and producing heat-induced surface defects. The results of the linear sweep voltammetry measurements, showing the polarization curves of bulk $\mathrm{MoS}_{2}$, hydrothermal MoS , $\mathrm{MoS}_{2} / \mathrm{C}$ hybrids, and Pt/C, are shown in Fig. 4(e). The $\mathrm{MoS}_{2} / \mathrm{C}$ hybrids exhibit a higher overpotential $(216 \mathrm{mV})$ and a lower Tafel slope $(64$ $\mathrm{mV} \operatorname{dec}^{-1}$ ) than other samples [Fig. 4(f)]. Hasani et al. [40] demonstrated a solar-driven HER sensor having a heterojunction formed by thermally decomposed n-type $\mathrm{MoS}_{2}$ on a p-type $\mathrm{Si}$. This sensor shows the highest catalytic activity with the lowest Tafel slope of $65 \mathrm{mV} \mathrm{dec}{ }^{-1}$, when an appropriate $\mathrm{MoS}_{2}$ thin-film thickness $(16.8 \mathrm{~nm})$ is used.

\subsection{Strain and haptic sensors}

The previously reported methods of TMDC-based strain sensor fabrication used thin films grown using CVD, with several subsequent photolithography steps to pattern the strain gauge [41,42]. Park et al. [23] demonstrated the direct pattern formation of a $\mathrm{MoS}_{2}$-based strain gauge and proposed that a lithography-free approach can be applied to develop a three-axis strain gauge rosette. The application of an external force on the $\mathrm{MoS}_{2}$ strain gauge causes strain-induced deformation of the conductive pathways, which changes the electrical conductivity of the material [Fig. 5(a)]. Notably, the relationship between the conductivity and strain is linear, and the gauge operates reversibly, 
without hysteresis, at a strain $<1.67 \%$. Therefore, the range of the strain is restricted to the linear regime $(\approx 1.5 \%)$, and the mechanical response of the strain gauge shows a stable response over 1000 repeated cycles [Fig. 5(b)]. When mounted on a human wrist, this three-axis strain gauge rosette can simultaneously respond in unknown $X^{o}$ and $Y^{o}$ directions [Fig. 5(c)]. The time-resolved resistance response of the rosette shows an omnidirectional sensing ability.

Direct-pattern formation by photothermal decomposition is used to fabricate self-powering haptic sensors that use an $\mathrm{MoS}_{2}$ active layer. Park et al. [24] fabricated large-scale patterned $\mathrm{MoS}_{2}$ thin films and developed strain induced crumpled $\mathrm{MoS}_{2}$. The crumpled $\mathrm{MoS}_{2}$ has distinct characteristics compared to the pristine $\mathrm{MoS}_{2}$. A widening in the $\mathrm{MoS}_{2}$ lattice and a decrease in the orbital overlap increase the work function of the sensor; these changes increase the chargetransfer effect during the generation of self-powering signal, i.e., the triboelectric current generation. Hence, the haptic sensor is selfpowered and includes a triboelectric touchpad on a latex glove. The 4 $\times 4$ arrayed, crumpled $\mathrm{MoS}_{2}$ haptic touch sensor has a time-dependent mapping trajectory, according to the movement of a stylus [Fig. 5(d)].

\section{Summary}

This review covers a wide range of large-scale, inexpensive, and simple methods for synthesizing TMDC thin films from solutions with direct-pattern formation, in addition to elucidating their practical applications. Various precursor deposition methods have been developed to increase the film area and modulate the solution composition, which yields the appropriate coating conditions for large-scale fabrication. Thus, the thickness of the TMDC film is easily modulated by adjusting the precursor concentration. Notably, direct formation of the TMDC patterns is also achieved using the solution-phase precipitation and photothermal decomposition. These processes yield vertically stacked TMDC-based heterostructures, without complex processing steps. The synthesis of TMDCs from solutions can be practically applied to readily fabricate devices, such as FETs, photodetectors, HER catalysts, diodes, and mechanical sensors.

However, the TMDC thin film synthesis method covered in this review is still problematic to be applied to high performance electronic devices because of the small TMDC grain size. Therefore, the development of another methodology for the mass production of highly crystallinity of TMDC thin films is crucial for their applications in the semiconductor industry and researches.

\section{Acknowledgements}

This research was supported by the Korea Institute of Science and Technology (KIST) Institutional Program and supported by the Tech-nology Innovation Program (20011317) funded by the Ministry of Trade Industry \& Energy.

\section{References}

[1] Y. Kim, S. S. Cruz, K. Lee, B. O. Alawode, C. Choi, Y. Song, J. M. Johnson, C. Heidelberger, W. Kong, and S. Choi, Nature 544, 340 (2017).

[2] H. Schmidt, S. Wang, L. Chu, M. Toh, R. Kumar, W. Zhao, A. H. Neto, J. Martin, S. Adam, B. Ozyilmaz, and G. Eda, Nano. Lett. 14, 1909 (2014).
[3] N. Perea-López, A. L. Elías, A. Berkdemir, A. Castro-Beltran, H. R. Gutiérrez, S. Feng, R. Lv, T. Hayashi, F. López-Urías, S. Ghosh, B. Muchharla, S. Talapatra, H. Terrones, and M. Terrones, Adv. Funct. Mater. 23, 5511 (2013).

[4] S. B. Desai, S. R. Madhvapathy, A. B. Sachid, J. P. Llinas, Q. Wang, G. H. Ahn, G. Pitner, M. J. Kim, J. Bokor, and C. Hu, Science 354, 99 (2016).

[5] S. Bae, H. Kim, Y. Lee, X. Xu, J. S. Park, Y. Zheng, J. Balakrishnan, T. Lei, H. R. Kim, and Y. I. Song, Nat. Nanotechnol. 5, 574 (2010).

[6] T. Kobayashi, M. Bando, N. Kimura, K. Shimizu, K. Kadono, N. Umezu, K. Miyahara, S. Hayazaki, S. Nagai, and Y. Mizuguchi, Appl. Phys. Lett. 102, 023112 (2013).

[7] J. H. Lee, E. K. Lee, W. J. Joo, Y. Jang, B. S. Kim, J. Y. Lim, S. H. Choi, S. J. Ahn, J. R. Ahn, and M. H. Park, Science 344, 286 (2014).

[8] A. K. Geim and I. V. Grigorieva, Nature 499, 419 (2013).

[9] S. Tongay, J. Zhou, C. Ataca, K. Lo, T. S. Matthews, J. Li, J. C. Grossman, and J. Wu, Nano Lett. 12, 5576 (2012).

[10] G. Iannaccone, F. Bonaccorso, L. Colombo, and G. Fiori, Nat. Nanotechnol. 13, 183 (2018).

[11] J. Yoon, W. Park, G. Y. Bae, Y. Kim, H. S. Jang, Y. Hyun, S. K. Lim, Y. H. Kahng, W. K. Hong, B. H. Lee, and H. C. Ko, Small 9, 3295 (2013).

[12] J. Pu, Y. Yomogida, K. K. Liu, L. J. Li, Y. Iwasa, and T. Takenobu, Nano Lett. 12, 4013 (2012).

[13] H. Yu, M. Liao, W. Zhao, G. Liu, X. J. Zhou, Z. Wei, X. Xu, K. Liu, Z. Hu, K. Deng, S. Zhou, J. A. Shi, L. Gu, C. Shen, T. Zhang, L. Du, L. Xie, J. Zhu, W. Chen, R. Yang, D. Shi, and G. Zhang, ACS Nano 11, 12001 (2017).

[14] Y. Kim, A. R. Kim, G. Zhao, S. Y. Choi, S. C. Kang, S. K. Lim, K. E. Lee, J. Park, B. H. Lee, M. G. Hahm, D. H. Kim, J. Yun, K. H. Lee, and B. Cho, ACS Appl. Mater. Inter. 9, 37146 (2017).

[15] Y. Xue, Y. Zhang, Y. Liu, H. Liu, J. Song, J. Sophia, J. Liu, Z. Xu, Q. $\mathrm{Xu}, \mathrm{Z}$. Wang, J. Zheng, Y. Liu, S. Li, and Q. Bao, ACS Nano 10, 573 (2016).

[16] N. Choudhary, J. Park, J. Y. Hwang, H. S. Chung, K. H. Dumas, S. I. Khondaker, W. Choi, and Y. Jung, Sci. Rep. 6, 25456 (2016).

[17] A. Pant, Z. Mutlu, D. Wickramaratne, H. Cai, R. K. Lake, C. Ozkan, and S. Tongay, Nanoscale 8, 3870 (2016).

[18] A. Giri, G. Park, H. Yang, M. Pal, J. Kwak, and U. Jeong, Adv. Mater. 30, 1707577 (2018).

[19] C. Ahn, J. Lee, H. U. Kim, H. Bark, M. Jeon, G. H. Ryu, Z. Lee, G. Y. Yeom, K. Kim, J. Jung, Y. Kim, C. Lee, and T. Kim, Adv. Mater. 27, 5223 (2015).

[20] J. Yang, Y. Gu, E. Lee, H. Lee, S. H. Park, M. H. Cho, Y. H. Kim, Y. H. Kim, and H. Kim, Nanoscale 7, 9311 (2015).

[21] H. Yang, A. Giri, S. Moon, S. Shin, J. M. Myoung, and U. Jeong, Chem. Mater. 29, 5772 (2017).

[22] J. B. Lee, Y. R. Lim, A. K. Katiyar, W. Song, J. Lim, S. Bae, T. W. Kim, S. K. Lee, and J. H. Ahn, Adv. Mater. 31, e1904194 (2019).

[23] S. Park, A. Lee, K. H. Choi, S. K. Hyeong, S. Bae, J. M. Hong, T. W. Kim, B. H. Hong, and S. K. Lee, ACS Nano 14, 8485 (2020).

[24] S. Park, J. Park, Y. G. Kim, S. Bae, T. W. Kim, K. I. Park, B. H. Hong, C. K. Jeong, and S. K. Lee, Nano Energy 78, 105266 (2020).

[25] S. J. Hibble and M. R. Feaviour, J. Mater. Chem. 11, 2607 (2001).

[26] N. Kondekar, M. G. Boebinger, M. Tian, M. H. Kirmani, and M. T. McDowell, ACS Nano 13, 7117 (2019).

[27] K. K. Liu, W. Zhang, Y. H. Lee, Y. C. Lin, M. T. Chang, C. Y. Su, C. S. Chang, H. Li, Y. Shi, H. Zhang, C. S. Lai, and L. J. Li, Nano Lett. 12, 1538 (2012). 
[28] J. G. Kim, W. S. Yun, S. Jo, J. Lee, and C. H. Cho, Sci. Rep. 6, 29813 (2016).

[29] L. Liang and V. Meunier, Nanoscale 6, 5394 (2014).

[30] A. S. George, Z. Mutlu, R. Ionescu, R. J. Wu, J. S. Jeong, H. H. Bay, Y. Chai, K. A. Mkhoyan, M. Ozkan, and C. S. Ozkan, Adv. Funct. Mater. 24, 7461 (2014).

[31] R. Ionescu, B. Campbell, R. Wu, E. Aytan, A. Patalano, I. Ruiz, S. W. Howell, A. E. McDonald, T. E. Beechem, K. A. Mkhoyan, M. Ozkan, and C. S. Ozkan, Sci. Rep. 7, 6419 (2017).

[32] Y. R. Lim, J. K. Han, S. K. Kim, Y. B. Lee, Y. Yoon, S. J. Kim, B. K. Min, Y. Kim, C. Jeon, S. Won, J. H. Kim, W. Song, S. Myung, S. S. Lee, K. S. An, and J. Lim, Adv. Mater. 30, 1705270 (2018).

[33] Y. R. Lim, W. Song, J. K. Han, Y. B. Lee, S. J. Kim, S. Myung, S. S. Lee, K. S. An, C. J. Choi, and J. Lim, Adv. Mater. 28, 5025 (2016).

[34] S. K. Lee, J. B. Lee, J. Singh, K. Rana, and J. H. Ahn, Adv. Mater. 27, 4142 (2015).

[35] J. Zhu, J. Wu, Y. Sun, J. Huang, Y. Xia, H. Wang, H. Wang, Y. Wang, Q. Yi, and G. Zou, RSC Adv. 6, 110604 (2016).

[36] A. Ebnonnasir, B. Narayanan, S. Kodambaka, and C. V. Ciobanu,
Appl. Phys. Lett. 105, 031603 (2014).

[37] S. L. Li, K. Wakabayashi, Y. Xu, S. Nakaharai, K. Komatsu, W. W. Li, Y. F. Lin, A. Aparecido-Ferreira, and K. Tsukagoshi, Nano Lett. 13, 3546 (2013).

[38] J. Na, M. Shin, M. K. Joo, J. Huh, Y. J. Kim, H. J. Choi, J. H. Shim, and G. T. Kim, Appl. Phys. Lett. 104, 062901 (2014).

[39] H. Deng, C. Zhang, Y. Xie, T. Tumlin, L. Giri, S. P. Karna, and J. Lin, J. Mater. Chem. A 4, 6824 (2016).

[40] A. Hasani, Q. V. Le, M. Tekalgne, M. J. Choi, T. H. Lee, H. W. Jang, and S. Y. Kim, NPG Asia Mater. 11, 1 (2019).

[41] M. Park, Y. J. Park, X. Chen, Y. K. Park, M. S. Kim, and J. H. Ahn, Adv. Mater. 28, 2556 (2016).

[42] Y. J. Park, B. K. Sharma, S. M. Shinde, M. S. Kim, B. Jang, J. H. Kim, and J. H. Ahn, ACS Nano 13, 3023 (2019).

[43] Z. Huang, W. Luo, L. Ma, M. Yu, X. Ren, M. He, S. Polen, K. Click, B. Garrett, J. Lu, K. Amine, C. Hadad, W. Chen, A. Asthagiri, and Y. Wu, Angew. Chem. Int. Ed. Engl. 54, 15181 (2015).

[44] T. Zhang, L. B. Kong, Y. H. Dai, K. Yan, M. Shi, M. C. Liu, Y. C. Luo, and L. Kang, Chem. Asian J. 11, 2392 (2016). 